\title{
5 Research Square

\section{Comparison of Two Intravenous Fluid Management Strategies in COVID-19 Patients in Hubei, China: A Retrospective Multicenter Study}

\section{Yaping Yuan}

Chinese PLA General Hospital

Jionghe Wu

Chinese PLA General Hospital

Runsheng Wang

Chinese PLA General Hospital

\section{Zhanling Wu}

The Central Hospital of Xiaogan

\section{Lei Pan}

binzhou medical university hospital

\section{Jing Cheng}

The Central Hospital of Xiaogan

\section{Yifan Que}

Chinese PLA General Hospital

\section{Jing Deng}

Barts Heart Centre and University College London

\section{Christopher Chang}

University of California Davis

\section{Guogang Xu}

Chinese PLA General Hospital https://orcid.org/0000-0002-3056-9578

Hongxia Li ( $\nabla$ lhxsis@sina.com )

Chinese PLA General Hospital

\section{Research}

Keywords: SARS-Cov-2, COVID-19, Intravenous Fluid Management Strategies

Posted Date: August 12th, 2020

DOl: https://doi.org/10.21203/rs.3.rs-55580/v1 
License: (c) (i) This work is licensed under a Creative Commons Attribution 4.0 International License. Read Full License 


\section{Abstract \\ Background}

Optimal fluid management in patients with COVID-19 has not been reported. This retrospective, multicenter study investigated the impact of intravenous infusion volume in the early stage of COVID-19 on clinical outcomes.

\section{Methods}

127 patients from two tertiary hospitals were separated into the "conservative" and "liberal" groups based on average daily intravenous infusion volume within the first seven days after admission. Basic information, demographic and epidemiological characteristics, laboratory findings, treatments, and outcome measures were retrieved from medical records. The disease progression and prognosis were analyzed and compared.

\section{Results}

The average daily intravenous infusion volume within 7 days was $500(150-700) \mathrm{ml} /$ day in the conservative-strategy group $(n=87)$, and $1100(1000-1288) \mathrm{ml} /$ day in the liberal-strategy group $(n=40)$ $(p<0.001)$. There were no statistical differences in median age, male-to-female ratio, epidemiology, laboratory findings on admission, comorbidities, and average daily urine output within the seven days ( $p>$ $0.05)$. The final $\mathrm{K}^{+}$in the liberal group was slightly higher than that at admission, and the final hematocrit level in the conservative group had a significant difference than that at admission $(p<0.05)$. The mean $( \pm$ SD) duration of hospitalization was $22.41 \pm 11.99$ days in the conservative group and $25.28 \pm 12.08$ days in the liberal group $(p=0.120)$. However, compared to the liberal group, conservative group had statistically lower rates of disease progression ( $9.3 \%$ vs $37.5 \%, p<0.001)$, mechanical ventilation ( $2.3 \%$ vs $27.5 \%, p<0.001)$ and in-hospital mortality $(2.3 \%$ vs $15.0 \%, p=0.012)$.

\section{Conclusions}

Although there appeared to be no significant difference in the duration of hospitalization between using conservative and liberal fluid management strategies, the former was associated with lower rates of disease progression, mechanical ventilation and in-hospital mortality without increased nonpulmonaryorgan dysfunction. These results support the importance of implementing conservative intravenous fluid infusion in the early stage of COVID-19.

\section{Background}


Since its outbreak in Wuhan, COVID-19 has spread globally, causing over 11 million infections and 537,000 deaths as of July 6, 2020. ${ }^{1,2}$ The World Health Organization (WHO) had declared COVID-19 a pandemic in March, 2020. ${ }^{3}$ Despite the gradual decrease in cases in some countries, the pandemic has not yet been brought under control in many other regions of the world.

Studies on its clinical presentation, laboratory and pathological findings along with its clinical outcome have shown that a large proportion of patients died of SARS-CoV-2 associated acute lung injury (ALI) or acute respiratory distress syndrome (ARDS). ${ }^{4,5}$ Yet, the optimal fluid management for ALI/ARDS has not been determined. ${ }^{6-9}$ Most practitioners believed that appropriate restriction of fluid input is beneficial to a good prognosis of ARDS, and previous studies have supported that a conservative fluid-management strategy for patients with ALI or ARDS may alleviate lung edema, improve lung function, shorten Intensive Care Unit (ICU) stay, decrease duration of mechanical ventilation, and improve prognosis. ${ }^{10-12}$ However, some scholars believed that possible risks of this approach are the decrease of cardiac output and deterioration of nonpulmonary-organ function. ${ }^{13-16}$

The incidence of advanced ARDS in patients with COVID-19 pneumonia has been reported to be over $20 \% .{ }^{17}$ Nevertheless, the impact of fluid restriction in the early stages of COVID-19 on clinical outcomes is unclear. ${ }^{18}$ Current evidence is insufficient to support the use of either a liberal or conservative intravenous fluid strategy in the early stages. In this study, we enrolled patients with confirmed COVID-19 from two hospitals in the epicenter province of Hubei (with Wuhan as its capital) and investigated the impact of the two strategies on the outcomes in COVID-19 patients.

\section{Methods}

\section{Study design and participants}

We conducted a retrospective, cross-sectional, multicenter study focusing on intravenous fluid management in patients diagnosed with COVID-19 from January 1 to April 1, 2020, recruited from the Affiliated Hospital of Wuhan University of Science and Technology and Huanggang Central Hospital, two tertiary hospitals in Hubei, China. This study was approved by the ethics committees of the two hospitals. A total of 236 patients with unexplained pneumonia on general wards in the two hospitals were randomly selected as the initial study population. They would then be further checked with the following inclusion and exclusion criteria.

Based on the clinical diagnostic standards in the New Diagnosis and Treatment Scheme for Novel Coronavirus Infected Pneumonia (Trial Edition 7) ${ }^{19}$ issued by the National Health Commission of the People's Republic of China, the inclusion criteria were as follows: 1, their COVID-19 infection was confirmed by SARS-CoV-2 positive finding by real-time polymerase chain reaction (RT-PCR) according to WHO interim guidance using nasal and/or throat swabs. 2, their COVID-19 pneumonia was further confirmed by typical chest computerized tomography (CT) findings. 
Those patients who met the following criteria were excluded from the study: 1, without complete laboratory data, including blood counts, blood biochemistry and coagulation parameters. 2 , without complete physician's orders sheet. 3, with fewer than seven days' in-hospital stay. 4, having developed shock within seven days since hospitalization. 5 , with severe cardiovascular diseases on admission, such as acute myocardial infarction or congestive heart failure. 6 , with severe renal impairment, such as acute kidney injury. 7, respiratory failure on admission or requiring mechanical ventilation. And/or 8 , with respiratory infections caused by other viruses, including influenza A virus, influenza B virus and respiratory syncytial virus.

\section{Study Procedures}

Demographic characteristics, epidemiological history, clinical manifestation, daily intravenous fluid administration and urine output within seven days after admission, admission assessment (curb-65 score), laboratory data, treatment programs and outcome measures were extracted from qualified patients' medical records. Clinical outcomes were followed up to May 1, 2020. Patients were divided into two groups according to the average daily intravenous infusion volume within seven days after admission. Those with an average daily intravenous infusion volume of $<1000 \mathrm{ml}$ were assigned to the conservative-strategy group whereas those with the volume of $\geq 1000 \mathrm{ml}$ to the liberal-strategy group. All data were separately obtained by two authors, and when necessary, missing data were re-collected through communications with attending physicians and other medical personnel. Through comparative analyses of the laboratory data and outcomes of the two groups, the impact of intravenous infusion volume on progression and prognosis was observed. Progression of the disease was assessed in terms of an changed curb-65 score.

\section{Outcomes}

In this study, we calculated average daily intravenous fluid administration and urine output of seven days after admission, and collected the epidemiological data (i.e., clear or unclear contact history and illness onset to admission), admission assessment (curb-65 Score), coexisting illnesses, laboratory data, medical treatments and clinical outcomes. Our main observed outcomes included duration of hospitalization, organ functional changes, the rate of disease progression and the necessity for mechanical ventilation. The secondary outcome was in-hospital mortality.

\section{Statistical Analysis}

For continuous variables, such as age and average daily urine volume within seven days, mean ( $\pm S D$ ) was used for normally distributed data and median with interquartile range for non-normally distributed data, followed by t-test and non-parametric tests when appropriate. Categorical variables such as chronic medical illness and in-hospital mortality were expressed as number (\%) and compared using the $\chi^{2}$ test. For laboratory results, we also assessed whether the measurements were outside the normal range. All analyses were performed using SPSS version 23.0 (IBM Corporation, Armonk, NY, USA). A two-tailed value of $p<0.05$ was considered statistically significant. 


\section{Results}

\section{Enrollment and Exclusions}

A total of 236 patients with unexplained pneumonia were initially enrolled during screening. Figure 1 shows the reasons for subsequent exclusion of 109 patients. First excluded were 46 patients for having no RT-PCR test or negative test results. Sixty-three patients were excluded for other reasons such as lacking laboratory data or complete physician's orders sheet and duration of hospitalization fewer than seven days. Some of the patients had more than one reason for exclusion. Of 127 patients eventually included, 87 patients received conservative fluid administration while 40 liberal fluid administration.

\section{Baseline characteristics}

The baseline characteristics of the 127 patients with COVID-19 are provided in Table 1. The two groups were similar with respect to demographic characteristics, epidemiological history, time from onset of illness to admission, disease severity on admission, organ dysfunction, coexisting illnesses and treatment programs (all $p>0.05$ ). There were no significantly statistical differences in the results of laboratory data on admission between the two groups (all $p>0.05$ ).

\section{Main outcome measures}

The average daily intravenous infusion volume over seven days was $500(150-700) \mathrm{ml} /$ day in the conservative group, as compared to 1100 (1000-1288) $\mathrm{ml} /$ day in the liberal group $(p<0.001)$. There was no significant difference between the two groups in the average daily urinary output during 7 days after admission (1514.93 $\pm 137.79 \mathrm{ml} /$ day vs. $1511.23 \pm 243.28 \mathrm{ml} /$ day, $p=0.751$ ) (Table 2 ).

In the final laboratory examination after seven days of fluid management and before discharge, the lymphocyte count and albumin in the conservative group were higher than those in the liberal group (all $p$ $<0.05$ ). In addition, we found that urea nitrogen value and ESR were lower in the conservative group (all $p$ $<0.05$ ). No significant differences were found in hematocrit, bilirubin, aminotransferases, creatinine, CRP, NT-pro BNP, ESR and other laboratory results between the two groups (all $p>0.05$ ) (Table 2). In the intragroup comparison of laboratory tests, the mean final $\mathrm{K}^{+}$in the liberal group was higher than that at admission, and the mean final hematocrit level in the conservative group was lower than that at admission (all $p<0.05$ ), but within the normal range. In addition, the hematocrit, $\mathrm{Na}^{+}$in the liberal group and $\mathrm{K}^{+}, \mathrm{Na}^{+}$in the conservative group showed no difference (all $p>0.05$ ).

The duration of hospitalization was $22.41 \pm 11.99$ days in the conservative strategy group and $25.28 \pm 12.08$ days in the liberal group $(p=0.120)$. However, when compared to the liberal group, the conservative group was found to have statistically lower rates of disease progression $(9.3 \%$ vs $37.5 \%, p<$ $0.001)$, mechanical ventilation $(2.3 \%$ vs $27.5 \%, p<0.001)$ and in-hospital mortality $(2.3 \%$ vs $15.0 \%, p=$ 0.012) (Table 2). 


\section{Discussion}

While knowledge regarding epidemiologic features and diagnostic tools of COVID-19 is rapidly evolving, uncertainties surrounding various aspects of optimal management strategies persist. Front-line multidisciplinary experts are deeply concerned about the irregular use of antimicrobials and adjuvant drugs in the international guidelines, as this has resulted in an excessive amount of intravenous fluids in some patients in the short term. ${ }^{20}$ Whether fluid management should be introduced early in COVID-19 patients to slow down disease progression has not been studied. Relevant previous research into fluid management has mostly focused on patients with ARDS or in other critical conditions. In a study in 416 patients with COVID-19, Shi et al ${ }^{17}$ reported an incidence of ARDS as high as $23.3 \%$. A considerable number of COVID-19 patients died of respiratory failure associated ALI /ARDS. ${ }^{4,21}$

To the best of our knowledge, this study has been the first to focus on the relationship between early intravenous fluid volume and prognosis of COVID-19. It was conducted by examining the medical records of patients during the initial outbreak of COVID-19 in two hospitals in Hubei Province from January to April 2020. In this retrospective study, we chose the daily intravenous infusion volume as a quantitative measure. Although we did not detect a significant difference between the conservative and liberal strategies of intravenous fluid management on the duration of hospitalization, the conservative strategy was significantly associated with lower rates of disease progression, mechanical ventilation and hospital mortality. Therefore, our data appear to suggest that a conservative intravenous fluid strategy leads to fewer complications and better prognosis than a liberal intravenous fluid strategy when managing COVID19 patients. We speculate that the worse prognosis in the liberal group might be caused by a side effect of over intravenous fluid infusion, resulting in pulmonary interstitial edema.

No significant differences were found in the WBC, hemoglobin, hematocrit levels and other laboratory results between the two groups. The available data are not sufficient to distinguish among these or offer any other potential explanations.

However, during the period studied, most patients' food and drink oral intake was based on their personal appetite and not quantified. The patients' body weight was not monitored, either. These may affect the accuracy in assessing body water retention and need to be addressed in future study.

Although the mean blood urea nitrogen level was slightly lower in the conservative group than that in the liberal group, there were no significant differences in the creatinine level, cardiac and renal function between the two groups. In addition, the conservative strategy was associated with a slightly higher lymphocyte count and albumin level, which might be related to mild dehydration in the patients. The intragroup comparison of laboratory tests showed that there was no dehydration in the conservative strategy and both groups had anhydrous electrolyte imbalance.

In summary, our initial study suggests that conservative intravenous fluid management may result in a favorable prognosis of COVID-19 within the first seven days after patients' admission. Therefore, clinical 
treatment may need considering the total amount of daily intravenous infusion in such patients. This should be investigated in prospective and large-scale studies.

\section{Conclusions}

Although there appeared to be no significant difference in the duration of hospitalization between using conservative and liberal fluid management strategies, the former was associated with lower rates of disease progression, mechanical ventilation and in-hospital mortality without increased nonpulmonaryorgan dysfunction. These results support the importance of implementing conservative intravenous fluid infusion in the early stage of COVID-19.

\section{Abbreviations}

WBC: White blood cell count, PT:Prothrombin time, ALT:Alanine aminotransferase, AST:Aspartate aminotransferase, LDH:Lactic dehydrogenase, CRP:C-reactive protein, hs-CRP:High-sensitivity C-reactive protein, NT-proBNP:N-terminal pro-brain natriuretic peptide, PCT:Procalcitonin, ESR:Erythrocyte sedimentation rate.

\section{Declarations}

\section{Ethical approval and consent to participate:}

This study (S2020-063-01) was approved by the Ethics Committee of Chinese PLA General Hospital. Patient consent was obtained upon hospitalization according to government policy.

\section{Consent for publication:}

Not applicable.

\section{Availability of data and materials:}

The datasets used and analyzed during the current study are available from the corresponding author on reasonable request.

\section{Competing interests:}

The authors declare that they have no competing interests.

\section{Funding:}

This study was funded by Beijing Municipal Natural Science Foundation General Program (CN, 7192197). 


\section{Authors' Contributions:}

$H L$ and GX conceptualized the paper. YY and JW analyzed the data with input from RW, ZW, LP, JC, YQ and JD. The data was collected by ZW, LP, JC, YQ and JD. YY, JW and RW wrote the initial draft with all authors providing critical feedback and edits to subsequent revisions. All authors approved the final draft of the manuscript. CC, HL and GX are the guarantor. The corresponding authors attest that all listed authors meet authorship criteria and that no others meeting the criteria have been omitted.

\section{Acknowledgments:}

We thank all the patients and their family, and the clinical staff who treated the patients in Xiaogan and Huanggang City.

\section{References}

1 World Health Organization. WHO director-general's opening remarks at the media briefing on COVID-1925 March 2020. https://www.who.int/dg/speeches/detail/who-director-general-s-opening-remarks-at-themedia-briefing-on-covid-19-25-march-2020. Accessed March 30, 2020.

2 https://www.who.int/docs/default-source/coronaviruse/situation-reports/20200601-covid-19-sitrep133.pdf?sfvrsn=9a56f2ac_4.

3 World Health Organization. WHO director-general's opening remarks at the media briefing on COVID-1911 March 2020. https://www.who.int/dg/speeches/detail/who-director-general-s-opening-remarks-at-themedia-briefing-on-covid-19-11-march-2020. Accessed March 30, 2020.

4 Ruan, Q., Yang, K., Wang, W., Jiang, L. \& Song, J. Clinical predictors of mortality due to COVID-19 based on an analysis of data of 150 patients from Wuhan, China. Intensive Care Med46, 846-848, doi:10.1007/s00134-020-05991-x (2020).

$5 \mathrm{Xu}, \mathrm{Z}$. et al. Pathological findings of COVID-19 associated with acute respiratory distress syndrome. The Lancet Respiratory Medicine8, 420-422, doi:10.1016/s2213-2600(20)30076-x (2020).

6 LD, H. Fluid management strategy in acute lung injury. Am Rev Respir Dis 1992145, 988-989 (1992).

7 TM, H. ARDS: the therapeutic dilemma. Chest 97, 1025 (1990).

8 Schuller D, M. J., Caladrino FS, Schuster DP. Fluid balance during pulmonary edema: is fluid gain a marker or a cause of poor outcome? Chest 100, 1068-1075 (1991).

9 DP, S. The case for and against fluid restriction and occlusion pressure reduction in adult respiratory distress syndrome. New Horiz1, 478-488 (1993). 
10 National Heart, L. et al. Comparison of two fluid-management strategies in acute lung injury. $N$ Engl $J$ Med354, 2564-2575, doi:10.1056/NEJMoa062200 (2006).

11 Murphy, C. V. et al. The importance of fluid management in acute lung injury secondary to septic shock. Chest136, 102-109, doi:10.1378/chest.08-2706 (2009).

12 Keddissi, J. I., Youness, H. A., Jones, K. R. \& Kinasewitz, G. T. Fluid management in Acute Respiratory Distress Syndrome: A narrative review. Can J Respir Ther55, 1-8, doi:10.29390/cjrt-2018-016 (2019).

13 Silversides, J. A. et al. Conservative fluid management or deresuscitation for patients with sepsis or acute respiratory distress syndrome following the resuscitation phase of critical illness: a systematic review and meta-analysis. Intensive Care Med43, 155-170, doi:10.1007/s00134-016-4573-3 (2017).

14 Greg S. Martin, M. R. J. M., MD; Arthur P. Wheeler, MD; William D. Dupont, PhD; John A. Morris, MD; Gordon R. Bernard, MD. Albumin and furosemide therapy in hypoproteinemic patients with acute lung injury. Crit Care Med30, 2175-2182, doi:10.1097/01.CCM.0000025182.51800.ED (2002).

15 Zhang, Z., Ni, H. \& Qian, Z. Effectiveness of treatment based on PiCCO parameters in critically ill patients with septic shock and/or acute respiratory distress syndrome: a randomized controlled trial. Intensive Care Med41, 444-451, doi:10.1007/s00134-014-3638-4 (2015).

16 Acheampong, A. \& Vincent, J. L. A positive fluid balance is an independent prognostic factor in patients with sepsis. Crit Care19, 251, doi:10.1186/s13054-015-0970-1 (2015).

17 Shi, S. et al. Association of Cardiac Injury With Mortality in Hospitalized Patients With COVID-19 in Wuhan, China. JAMA Cardiol, doi:10.1001/jamacardio.2020.0950 (2020).

18 Kazory, A., Ronco, C. \& McCullough, P. A. SARS-CoV-2 (COVID-19) and intravascular volume management strategies in the critically ill. Proc (Bayl Univ Med Cent)0, 1-6, doi:10.1080/08998280.2020.1754700 (2020).

19 National Health Commission of the People's Republic of China. New diagnosis and treatment scheme for novel coronavirus infected pneumonia (Trial edition 7) (Chinese) [R/OL]. (2020-3-4).

20 YF, H., SJ, L. \& cases, D. Y. J. W. j. o. C. Clinical characteristics, diagnosis, and treatment of COVID-19: A case report. 8, 2325-2331, doi:10.12998/wjcc.v8.i11.2325 (2020).

21 Yang, X. et al. Clinical course and outcomes of critically ill patients with SARS-CoV-2 pneumonia in Wuhan, China: a single-centered, retrospective, observational study. The Lancet Respiratory Medicine8, 475-481, doi:10.1016/s2213-2600(20)30079-5 (2020).

\section{Tables}


Table 1. Baseline characteristics of patients with COVID-19

\begin{tabular}{llllr} 
Characteristics & $\begin{array}{l}\text { All patients } \\
(\mathbf{n}=127)\end{array}$ & $\begin{array}{l}\text { Conservative-strategy } \\
\text { group }(\mathbf{n = 8 7})\end{array}$ & $\begin{array}{l}\text { Liberal-strategy } \\
\text { group }(\mathbf{n = 4 0 )}\end{array}$ & $\begin{array}{c}\boldsymbol{p} \\
\text { Value }\end{array}$ \\
\hline Age, years (mean [SD]) & $\begin{array}{l}48.90 \pm \\
13.49\end{array}$ & $48.20 \pm 13.31$ & $50.40 \pm 13.91$ & 0.389 \\
\hline Sex (male) & $\begin{array}{l}62 / 127 \\
(48.8 \%)\end{array}$ & $38 / 87(43.7 \%)$ & $27 / 40(60.0 \%)$ & 0.087 \\
& & &
\end{tabular}

Epidemiological history

\begin{tabular}{lllll}
\hline Clear contact history & $63(49.6 \%)$ & $44(50.6 \%)$ & $19(47.5 \%)$ & 0.748 \\
\hline Unclear contact history & $64(50.4 \%)$ & $43(49.4 \%)$ & $21(52.5 \%)$ & 0.748 \\
\hline $\begin{array}{l}\text { Days from illness onset } \\
\text { to }\end{array}$ & $7(5-11)$ & $7(5-11)$ & $7(5-13)$ & 0.753 \\
$\begin{array}{l}\text { admission } \\
\text { adm }\end{array}$ & & &
\end{tabular}

Chronic medical illness

\begin{tabular}{lllll}
$\begin{array}{l}\text { Respiratory system } \\
\text { disease }\end{array}$ & $15(11.8 \%)$ & $10(11.5 \%)$ & $5(12.5 \%)$ & 0.541 \\
\hline $\begin{array}{l}\text { Cardiovascular system } \\
\text { disease }\end{array}$ & $33(26.0 \%)$ & $20(23.0 \%)$ & $13(32.5 \%)$ & 0.256 \\
\hline Chronic liver disease & $9(7.1 \%)$ & $7(8.0 \%)$ & $2(5.0 \%)$ & 0.418 \\
\hline Chronic kidney disease & 0 & 0 & 0 & 1.000 \\
\hline $\begin{array}{l}\text { Endocrine system } \\
\text { disease }\end{array}$ & $7(5.5 \%)$ & $4(4.6 \%)$ & $3(7.5 \%)$ & 0.385 \\
\hline
\end{tabular}

\section{Admission assessment} (curb-65 Score)

\begin{tabular}{|lllll|}
\hline 0 & $75(62.0 \%)$ & $57(65.5 \%)$ & $18(52.9 \%)$ & 0.132 \\
\hline 1 & $31(25.6 \%)$ & $18(20.7 \%)$ & $13(38.2 \%)$ & 0.132 \\
\hline $\begin{array}{l}\text { Medical treatment after } \\
\text { admission }\end{array}$ & $15(12.4 \%)$ & $12(13.8 \%)$ & $3(8.8 \%)$ & 0.132 \\
\hline Antibiotic treatment & $106(84.0 \%)$ & $73(83.9 \%)$ & $33(82.5 \%)$ & 0.843 \\
\hline Antiviral treatment & $124(97.7 \%)$ & $85(97.7 \%)$ & $39(97.5 \%)$ & 0.682 \\
\hline Glucocorticoids & $76(59.8 \%)$ & $50(57.5 \%)$ & $26(65.0 \%)$ & 0.421 \\
\hline $\begin{array}{l}\text { Intravenous } \\
\text { immunoglobulin }\end{array}$ & $61(48.0 \%)$ & $41(47.1 \%)$ & $20(50.0 \%)$ & 0.763 \\
\hline
\end{tabular}


Laboratory tests

\begin{tabular}{|c|c|c|c|c|}
\hline WBC $\left(\times 10^{9} / \mathrm{L}\right)$ & $\begin{array}{l}4.51(3.59- \\
6.63)\end{array}$ & $4.50(3.51-5.84)$ & $4.61(3.71-8.49)$ & 0.199 \\
\hline Hemoglobin (g/L) & $\begin{array}{l}130.56 \pm \\
20.86\end{array}$ & $131.68 \pm 20.37$ & $128.00 \pm 22.03$ & 0.387 \\
\hline Hematocrit (\%) & $\begin{array}{l}39.81 \\
(37.05- \\
43.23)\end{array}$ & $39.80(37.13-44.50)$ & 39.50 (35.98-42.83) & 0.377 \\
\hline Platelet count $\left(\times 10^{9} / \mathrm{L}\right)$ & $\begin{array}{l}166(123- \\
206)\end{array}$ & $167(134-201)$ & $149(114-216)$ & 0.575 \\
\hline $\begin{array}{l}\text { Lymphocyte count } \\
\left(\times 10^{9} / \mathrm{L}\right)\end{array}$ & $\begin{array}{l}1.06(0.75- \\
1.39)\end{array}$ & $1.11(0.79-1.48)$ & $0.89(0.72-1.30)$ & 0.065 \\
\hline PT (s) & $13.07 \pm 1.65$ & $12.90 \pm 1.70$ & $13.58 \pm 1.9$ & 0.068 \\
\hline $\mathrm{ALT}(\mathrm{U} / \mathrm{L})$ & $18(12-31)$ & $17(12-31)$ & $19(13-33)$ & 0.362 \\
\hline AST (U/L) & $24(18-31)$ & $22(18-28)$ & $28(23-32)$ & 0.054 \\
\hline Albumin (g/L) & $\begin{array}{l}38.3(35.5- \\
41.0)\end{array}$ & $38.5(36.1-41.0)$ & $37.5(34.8-41.2)$ & 0.268 \\
\hline Bilirubin (umol/L) & $\begin{array}{l}11.3(9.3- \\
15.9)\end{array}$ & $11.1(9.0-15.1)$ & $13.2(9.5-23.5)$ & 0.070 \\
\hline Urea nitrogen (mmol/L) & $\begin{array}{l}4.06(3.30- \\
5.18)\end{array}$ & $3.90(3.24-4.80)$ & $4.58(3.63-5.88)$ & 0.053 \\
\hline Creatinine (umol/L) & $\begin{array}{l}71.87 \pm \\
18.87\end{array}$ & $70.57 \pm 17.56$ & $72.53 \pm 22.07$ & 0.234 \\
\hline $\mathrm{K}^{+}(\mathrm{mmol} / \mathrm{L})$ & $\begin{array}{l}4.03(3.73- \\
4.37)\end{array}$ & $4.11(3.79-4.40)$ & $3.95(3.71-4.20)$ & 0.080 \\
\hline $\mathrm{Na}^{+}(\mathrm{mmol} / \mathrm{L})$ & $\begin{array}{l}140(138- \\
142)\end{array}$ & $140(138-143)$ & $139(138-141)$ & 0.096 \\
\hline LDH (U/L) & $\begin{array}{l}257.56 \pm \\
61.91\end{array}$ & $251.61 \pm 60.38$ & $275.67 \pm 60.41$ & 0.117 \\
\hline CRP (mg/L) & $\begin{array}{l}38.04 \pm \\
37.59\end{array}$ & $34.90 \pm 40.72$ & $44.33 \pm 32.38$ & 0.601 \\
\hline hs-CRP (mg/L) & $\begin{array}{l}16.38(4.08- \\
33.66)\end{array}$ & 10.40 (3.71-32.27) & $23.73(6.87-42.63)$ & 0.070 \\
\hline NT-pro BNP (pg/ml) & $\begin{array}{l}250.30 \pm \\
243.42\end{array}$ & $188.61 \pm 149.02$ & $324.33 \pm 312.58$ & 0.112 \\
\hline РCT (ng/ml) & $\begin{array}{l}0.20(0.11- \\
0.33)\end{array}$ & $0.22(0.11-0.33)$ & $0.17(0.11-0.36)$ & 0.627 \\
\hline $\operatorname{ESR}(\mathrm{mm} / \mathrm{h})$ & $\begin{array}{l}33.19 \pm \\
16.15\end{array}$ & $31.61 \pm 17.57$ & $37.41 \pm 11.10$ & 0.294 \\
\hline
\end{tabular}


Table 2. Main Outcome Variables of patients with COVID-19

\section{Characteristics}

Average daily intravenous fluid volume ( $\mathrm{ml} /$ day) over 1 st 7 days after admission

Average daily urine within 7 days $(\mathrm{ml})$

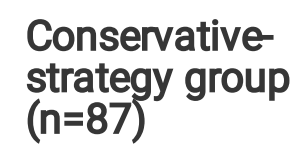

$500(150-700)$

$1514.93 \pm 137.79$

\section{Liberal-strategy group $(n=40)$}

$1100(1000-$ 1288)

$1511.23 \pm$ 243.28

\section{Laboratory tests}

WBC $\left(\times 10^{9} / \mathrm{L}\right)$

Hemoglobin $(\mathrm{g} / \mathrm{L})$

Hematocrit (\%)

Platelet count $\left(\times 10^{9} / \mathrm{L}\right)$

Lymphocyte count $\left(\times 10^{9} / \mathrm{L}\right)$

PT (s)

$\operatorname{ALT}(\mathrm{U} / \mathrm{L})$

AST (U/L)

Albumin (g/L)

Bilirubin (umol/L)

Urea nitrogen $(\mathrm{mmol} / \mathrm{L})$

Creatinine (umol/L)

$\mathrm{K}^{+}(\mathrm{mmol} / \mathrm{L})$

$\mathrm{Na}^{+}(\mathrm{mmol} / \mathrm{L})$

$\mathrm{LDH}(\mathrm{U} / \mathrm{L})$

CRP $(\mathrm{mg} / \mathrm{L})$

hs-CRP (mg/L)

NT-proBNP (pg/ml)

PCT (ng/ml)

$\operatorname{ESR}(\mathrm{mm} / \mathrm{h})$
$6.17(4.42-7.76)$

$6.29(4.69-$

$122.41 \pm 23.23$

0.607

$125.02 \pm 21.96$

$37.92 \pm 6.25$

$211.08 \pm 84.36$

$38.13 \pm 6.61$

0.895

$206.50 \pm 100.29$

0.827

$1.22 \pm 0.58$

$0.95 \pm 0.54$

0.025

$12.56 \pm 1.72$

33 (16-43)

$22(17-28)$

$35.9(32.5-39.2)$

$12.97 \pm 1.63$

0.413

34 (21-75)

0.299

24 (17-39)

0.235

$33.7(30.5-36.8) \quad 0.040$

$11.9(8.5-17.0)$

13.0(9.6-21.8)

0.441

4.11(3.20-5.56)

5.00 (4.09-9.06)

0.034

60.65 (51.35-71.05)

66.70 (51.7079.70)

0.283

$4.35 \pm 0.76$

0.145

$4.10 \pm 0.63$

$141(138-142)$

0.799

$141(139-143)$

211 (187-299)

0.924

229 (185-292)

$10.80(5.50-$

$57.42)$

$7.20(5.00-15.98)$

$5.00(2.48-$ 33.50)

$5.00(0.88-21.23)$

$433.32 \pm 431.04$

$391.25 \pm 557.74$

0.628

0.19 (0.09-0.46)

0.33 (0.13-0.59)

0.447

18.50 (15.25-41.75)

44.00 (28.75-

0.031 


\section{Progression of the disease}

\begin{tabular}{|lllr|} 
Disease progress & $8(9.3 \%)$ & $15(37.5 \%)$ & $<0.001$ \\
No progress & $78(90.7 \%)$ & $25(62.5 \%)$ & $<0.001$ \\
\hline Mechanical ventilation & $2(2.3 \%)$ & $11(27.5 \%)$ & $<0.001$ \\
\hline Cases transferred to ICU & $3(3.4 \%)$ & $12(30.0 \%)$ & $<0.001$ \\
\hline Total days in hospital & $22.41 \pm 11.99$ & $25.28 \pm 12.08$ & 0.120 \\
\hline Clinical outcome & & & \\
\hline Discharged & $85(97.7 \%)$ & $34(85.0 \%)$ & 0.012 \\
\hline Died & $2(2.3 \%)$ & $6(15.0 \%)$ & 0.012 \\
\hline
\end{tabular}

Table 3. Intra-group differences in laboratory tests of COVID-19 patients

\begin{tabular}{|c|c|c|c|c|}
\hline Groups & $\begin{array}{l}\text { Laboratory } \\
\text { tests }\end{array}$ & $\begin{array}{l}\text { laboratory tests on } \\
\text { admission }\end{array}$ & $\begin{array}{l}\text { Final laboratory } \\
\text { tests }\end{array}$ & $\stackrel{p}{\text { Value }}$ \\
\hline \multirow[t]{3}{*}{$\begin{array}{l}\text { Liberal-strategy group } \\
(n=40)\end{array}$} & $\begin{array}{l}\text { Hematocrit } \\
(\%)\end{array}$ & $39.50(35.98-42.83)$ & $\begin{array}{l}39.10(32.75- \\
43.05)\end{array}$ & 0.940 \\
\hline & $\mathrm{K}^{+}(\mathrm{mmol} / \mathrm{L})$ & $3.98 \pm 0.67$ & $4.35 \pm 0.76$ & 0.017 \\
\hline & $\begin{array}{l}\mathrm{Na}^{+} \\
(\mathrm{mmol} / \mathrm{L})\end{array}$ & 139 (137-141) & $141(138-142)$ & 0.054 \\
\hline \multirow[t]{3}{*}{$\begin{array}{l}\text { Conservative-strategy group } \\
(\mathrm{n}=87)\end{array}$} & $\begin{array}{l}\text { Hematocrit } \\
(\%)\end{array}$ & $39.80(37.13-44.50)$ & $\begin{array}{l}37.30(33.50- \\
41.93)\end{array}$ & 0.024 \\
\hline & $\mathrm{K}^{+}(\mathrm{mmol} / \mathrm{L})$ & $4.11(3.79-4.40)$ & $4.25(3.47-4.6)$ & 0.420 \\
\hline & $\begin{array}{l}\mathrm{Na}^{+} \\
(\mathrm{mmol} / \mathrm{L})\end{array}$ & $140(138-143)$ & $141(139-143)$ & 0.841 \\
\hline
\end{tabular}

Figures 


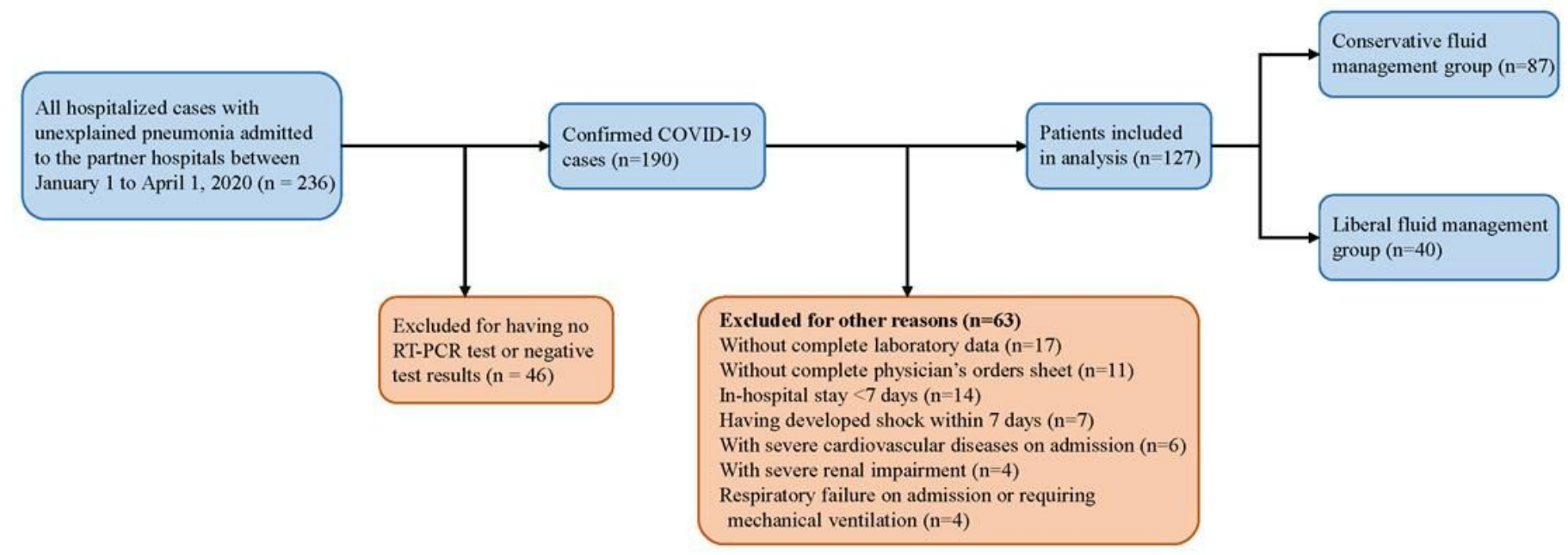

\section{Figure 1}

\section{Figure 1}

